\title{
Karakteristik Ibu dan Faktor Risiko Kejadian Kematian Bayi di Kabupaten Banjarnegara
}

\author{
Annisa Kusumawardani ${ }^{*}$, Sri Handayani*) \\ ${ }^{*}$ Fakultas Kesehatan Universitas Dian Nuswantoro \\ Korespondensi: yanih61@gmail.com
}

\begin{abstract}
Background: The number of infant mortality in Banjarnegara district became the highest compare with other districts in Central Java in 2012. In the last 5 years, infant mortality rate in this district has not been significantly declined. This study aims to analyze mother's characteristics and some risk factors associated to infant mortality in Banjarnegara.

Method: This study is survey with case control approach, sample consists of 47 mothers of having infant death before aged 24 days and 47 mothers as a control. Sample has been selected using purposive sampling. Primary data were collected by using face to face interview with questionnaire and secondary data collected based on mother health's book record in health center. Data was analyzed by frequency distribution and Chi-Square test.

Results: The Result showed that the risk factors which associated to infant death were baby with delivery complication, mother with history of anemia, baby with underweight birth, baby with asphyxia, congenital illness and premature birth. Whilst mother's age, mother's knowledge mother's education, parity, mother's weight, upper arm circumference of mother, mother with chronic diseases history, and bleeding experience during pregnant, hypertension, birth attendant, and mother's literacy had no significant association to infant death. This study recommends that health provider (especially village midwife) of health center have to prevent the risk factors of infant death by visiting mother with some risks intensively and routinely including Fe provision. The mother with some risks has to visit health center or health service in their village to check their infant.
\end{abstract}

Keywords: infant death, mother risk characteristics, risk factors

\begin{abstract}
ABSTRAK
Latar Belakang: Kabupaten Banjarnegara pada tahun 2012 menjadi Kabupaten dengan angka kematian bayi (AKB) tertinggi di Provinsi Jawa tengah. Dalam lima tahun terakhir angka kematian bayi sudah mengalami penurunan namun belum signifikan. Tujuan penelitian ini adalah untuk menganalisis karakteristik ibu dan beberapa faktor risiko yang berhubungan dengan kejadian kematian bayi di kabupaten Banjarnegara.

Metode: Penelitian ini merupakan penelitian survei dengan pendekatan kasus kontrol dengan jumlah kelompok kasus $47 \mathrm{ibu}$ dan kelompok kontrol 47 ibu. Sampel diambil secara purposive dengan kriteria inklusi kelompok kasus yaitu ibu yang mempunyai bayi meninggal sebelum berusia 24 hari di tahun 2017 dan tercatat di puskesmas Punggelan dan pejawaran. Data primer diambil dengan menggunakan kuesioner dengan teknik wawancara tatap muka. Data sekunder diambil dari buku catatan KIA ibu. Data dianalisis dengan menggunakan uji Chi-Square.

Hasil: Dari hasil penelitian didapatkan bahwa faktor risiko yang berhubungan dengan kejadian kematian bayi di Kabupaten Banjarnegara adalah komplikasi persalinan, riwayat anemia, berat bayi lahir rendah, asfiksia, kelainan kongenital, dan bayi lahir prematur. Sedangkan umur ibu pengetahuan ibu, Pendidikan ibu, Paritas, Jarak kehamilan, berat badan
\end{abstract}


ibu, lingkar lengan atas ibu, riwayat penyakit kronik ibu, perdarahan, hipertensi, penolong persalinan, tidak berhubungan secara signifikan dengan kejadian kematian bayi.

Diharapkan dari hasil penelitian ini petugas kesehatan dapat mencegah faktor risiko yang berhubungan dengan kematian bayi dengan cara menganjurkan dan mengunjungi ibu hamil untuk melakukan ANC tepat waktu dan lengkap termasuk pemberian tablet Fe kepada ibu dan memonitornya melalui petugas surveilance KIA.

Kata Kunci: kematian bayi, faktor risiko, karakteristik ibu hamil

\section{PENDAHULUAN}

Angka Kematian Bayi (AKB) adalah indikator derajat kesehatan didalam Sustainable Development Goal (SDGs) dan Rencana Pembangunan Jangka Menengah Nasional (RPJMN) 20152019.(1) Goal SDGs ke tiga yaitu Good Health and Well- being menjelaskan bahwa salah satu dampak yang diharapkan yaitu dituntaskannya kematian bayi dan balita melalui pencegahan yang ditargetkan pada tahun 2030. Semua negara diharapkan berpartisipasi untuk menekan angka kematian neonatal menjadi 12/1.000 KH serta angka kematian balita 25/1.000 KH. ${ }^{(1)}$ Provinsi Jawa Tengah termasuk dalam 6 besar daerah dengan AKB tertinggi di Indonesia. Dalam buku saku kesehatan Triwulan 2 Tahun 2016 Dinkes Provinsi Jawa Tengah terdapat 2370 kasus angka kematian bayi. $^{(2)}$ Kabupaten Banjarnegara pada tahun 2012 menjadi Kabupaten dengan angka kematian bayi tertinggi di Provinsi Jawa Tengah yaitu sebesar 18,16/1000 kelahiran hidup walaupun angka tersebut berada dibawah target, namun angka tersebut masih perlu diantisipasi agar angka tersebut tidak naik tiap tahunnya.

Angka kematian bayi di Indonesia tahun 2016 masih cukup tinggi yaitu 23,50/1000 kelahiran hidup, bahkan Indonesia menjadi peringkat tertinggi dibandingkan dengan Vietnam $(17,80 / 1000)$, Malaysia ( $12,90 / 1000)$, dan Thailand (9,40/1000). ${ }^{(1)}$ Target RPJMN 2015-2019 angka kematian bayi/1000 kelahiran hidup sebesar 24/1000 KH. Kebijakan lain yang direncanakan untuk menekan angka kematian bayi yaitu Indonesia neonatal action plan 2025 untuk menurunkan AKN dari target SDKI 2012 19/1000KH menjadi 9/1000KH. ${ }^{(1)}$ AKB merupakan indikator mengenai faktor risiko kejadian bayi mati, kualitas pelayanan ANC, status gizi ibu hamil, indikator program KIA dan KB, dan situasi lingkungan serta status ekonomi. ${ }^{(2)}$

Jumlah Angka Kematian bayi di Banjarnegara 5 tahun terakhir memang sudah mengalami penurunan namun belum signifikan, dimana pada tahun 2012 AKB sebesar 18,16/1000 KH, selanjutnya tahun 2013 sebesar 16,61/1000 kelahiran hidup, tahun 2014 adalah 12,6/1000 kelahiran 
hidup dan tahun 2015 menjadi 13,22/1000 kelahiran hidup serta pada tahun 2016 yaitu 13,17/1000 kelahiran hidup. ${ }^{(3)(4)}$ Kejadian kematian bayi di Banjarnegara pada Mei 2017 sebanyak 57 kasus, meningkat secara signifikan sampai bulan Agustus yaitu 101 kasus, dan terus meningkat sampai Desember menjadi 160 kasus serta total pada tahun 2017 sebesar 204 kasus atau 13,37/1000 kelahiran hidup. $^{(5)(6)}$

Berdasarkan kondisi geografi dan topografi sebagian besar wilayah Banjarnegara adalah dataran tinggi sehingga akan meningkatkan risiko kejadian kematian bayi karena akses ke pelayanan rujukan PONEK jauh dan fasilitas PONEK di Banjarnegara hanya ada 2 yaitu di Rumah Sakit Umum Daerah Hj. Anna Lasmanah dan Rumah sakit islam. Keterbatasan fasilitas pelayanan rujukan serta akses ke sarana pelayanan kesehatan disebagian wilayah yang secara geografis masih sulit dijangkau dan jarak yang terlalu jauh ke pelayanan kesehatan masih banyak terjadi di berbagai di wilayah cakupan kerja Puskesmas. Berdasarkan survei awal, terjadi beberapa kasus ibu yang melahirkan di perjalanan ketika menuju ke layanan kesehatan seperti puskesmas, bahkan ada yang sempat melahirkan didepan IGD dan di halaman parkir puskesmas
Salah satu kasus kematian bayi di Banjarnegara ialah kematian bayi kembar yang terjadi di bulan Januari tahun 2017 dengan faktor risiko yang teridentifikasi mempengaruhi kejadian kematian bayi,antara lain: berat badan Ibu hamil pada kehamilan 28 minggu hanya $45 \mathrm{~kg}$, Persalinan prematur/preterm (28 minggu) dan berat bayi lahir rendah (<2500gram), lingkar lengan atas $15 \mathrm{~cm}<23,5 \mathrm{~cm}$ (penilaian Lila minimal) dalam arti adalah ibu kurang gizi, Akses ke Pelayanan kesehatan sulit (jalan rusak dan jaraknya jauh), bidan salah mendeteksi risiko, fasilitas pelayanan kesehatan kurang memadai (tidak ada genset pada waktu persalinan listrik mati), serta keterbatasan fasilitas rujukan. ${ }^{(7)(8)}$

Tujuan umum penelitian ini adalah untuk mengetahui faktor internal dan eksternal yang berhubungan dengan kematian bayi. Tujuan khusus penelitian ini adalah mengetahui hubungan komplikasi persalinan, riwayat anemia, umur ibu, pengetahuan ibu, pendidikan ibu, paritas, jarak kehamilan, berat badan ibu, faktor LILA ibu, riwayat penyakit kronik ibu, perdarahan, hipertensi, penolong persalinan dan literasi ibu dengan kejadian kematian bayi. Selanjutnya mengetahui hubungan BBLR, asfiksia, kelainan kongenital dan bayi prematur terhadap kematian bayi. 


\section{METODE}

Penelitian ini merupakan penelitian survei dengan pendekatan kasus kontrol. Sampel dalam penelitian ini sebesar 47 kasus (ibu dengan kematian bayi yaitu ibu yang memiliki riwayat melahirkan bayi dan bayi meninggal sebelum berusia 24 hari dan 47 ibu untuk kelompok kontrol. Sampel diperoleh dengan menggunakan teknik purposive dengan menggunakan kriteria inklusi responden telah tercatat di Puskesmas maupun di Dinas Kesehatan Kabupaten Banjarnegara, sehingga dapat dicari alamatnya untuk diwawancarai, Responden dengan jarak tempat tinggalnya masih di wilayah cakupan Puskesmas Punggelan dan Puskesmas Pejawaran, Data kematian tercatat dalam kematian bayi pada tahun 2017. Data kasus diperoleh dengan menggunakan data kematian bayi yang ada di Dinas Kesehatan Banjarnegara sedangkan data kontrol diambil disekitar kasus. Agar mempunyai kesamaan karakteristik. Kesediaan untuk menjadi subjek penelitian dilakukan dengan menandatangani informed consent. Data penelitian terdiri dari data primer dengan menggunakan instrument kuesioner yang sebelumnya diuji validitas dan reliabilitasnya. Data sekunder diperoleh dari catatan buku KIA dan wawancara dengan petugas kesehatan ibu dan anak di puskesmas. Penelitian ini dilakukan di kabupaten Banjarnegara selama tiga bulan yaitu pada bulan April-Juni 2018. Variabel dalam penelitian ini adalah faktor eksternal terdiri dari komplikasi persalinan, riwayat anemia, umur ibu, pengetahuan ibu, Pendidikan ibu, Paritas, Jarak kehamilan, berat badan ibu, LILA, riwayat penyakit kronik ibu, perdarahan, hipertensi, penolong persalinan dan literasi ibu, sedangkan faktor internal terdiri dari BBLR, asfiksia, kelainan kongenital dan bayi prematur. Data dianalisis dengan menggunakan uji Chi-square.

\section{HASIL DAN PEMBAHASAN}

Tempat peneliti kematiaan ini dilakukan di beberapa puskesmas dengan kasus kematian bayi tinggi yaitu Puskesmas Punggelan 1 terletak di Jl. Raya Pasar Manis Rt.01/Rw.05, Kecamatan Punggelan, Kabupaten Banjarnegara, Provinsi Jawa Tengah, Indonesia. Sebagian besar wilayah kerja Puskesmas Punggelan 1 berada di daerah pedesaan dan akses kepelayanan kesehatan cukup berkelak-kelok, namun akses jalan baik. Puskesmas Punggelan 2 terletak di Dusun. Jombok, Kelurahan Petuguran, Kecamatan Punggelan, Kabupaten Banjarnegara, Provinsi Jawa Tengah. Akses Ke pelayanan kesehatan cukup curam dan transportasi umumnya jarang karena terletak di dataran tinggi. Puskesmas Banjarnegara 1 terletak J1. Serma Muklas Km. 1, Kecamatan Banjarnegara, 
Kabupaten Banjarnegara, Provinsi Jawa Tengah, Indonesia. Puskesmas Banjarnegara 1 terletak di daerah perkotaan Banjarnegara dan mudah di akses menggunakan angkutan umum. Puskesmas Banjarnegara 2 terletak di Kelurahan Semarang, Kec. Banjarnegara, Kabupaten Banjarnegara, Provinsi Jawa Tengah. Puskesmas 2 Banjarnegara juga terletak diaderah perkotaan dan mudah diakses oleh transportasi umum. Puskesmas Pejawaran terletak di Dusun Pejawaran, Kelurahan Penusupan, Kecamatan Pejawaran, Kabupaten Banjarnegara, Provinsi Jawa Tengah, berada di daerah dataran tinggi dengan wilayah kerja puskesmas yang cukup besar yaitu 17 Desa yang aksesnya cukup jauh antara desa satu dengan yang lainnya. Akses ke pelayanan puskesmas jika melalui jalan utama dapat diakses menggunakan transportasi umum, namun beberapa desa berada di daerah pelosok yang jaraknya ke pelayanan kesehatan cukup jauh sulit dan curam.

Berdasarkan hasil penelitian dari 47 kasus diketahui bahwa responden dengan umur beresiko tinggi antara kasus dan kontrol mempunyai prosentase yang sama yaitu 40,4\% begitu juga dengan kelompok beresiko rendah mempunyai prosentase yang sama yaitu $59,6 \%$. Adapun hasil uji statistik variabel dalam penelitian ini dapat dilihat pada tabel 1 dan 2.

Tabel 1. Uji Hubungan antara Karakteristik dan Faktor Risiko Responden dengan Kejadian Kematian Bayi

\begin{tabular}{|c|c|c|c|c|c|}
\hline \multirow[t]{2}{*}{ Variabel } & \multicolumn{2}{|c|}{ Kasus } & \multicolumn{2}{|c|}{ Kontrol } & \multirow[t]{2}{*}{ P-value (OR) } \\
\hline & $\mathrm{f}$ & $\%$ & $f$ & $\%$ & \\
\hline \multicolumn{6}{|l|}{ Umur } \\
\hline Beresiko tinggi & 19 & 40,4 & 19 & 40,4 & \multirow[t]{2}{*}{$0,760(1,261)$} \\
\hline Beresiko rendah & 28 & 59,6 & 28 & 59,6 & \\
\hline \multicolumn{6}{|l|}{ Pendidikan } \\
\hline Pendidikan Wajib Dasar & 45 & 95,7 & 46 & 97,9 & \multirow[t]{2}{*}{$0,557(0,489)$} \\
\hline Tingkat Pendidikan tinggi & 2 & 4,3 & 1 & 2,1 & \\
\hline \multicolumn{6}{|l|}{ Komplikasi persalinan } \\
\hline Ada & 11 & 23,4 & 7 & 14,9 & \multirow[t]{2}{*}{$0,001(11,613)$} \\
\hline Tidak & 36 & 76,6 & 40 & 85,1 & \\
\hline \multicolumn{6}{|l|}{ Riwayat anemia } \\
\hline Dengan Anemia & 25 & 53,2 & 12 & 25,5 & \multirow[t]{2}{*}{$0,006(3,314)$} \\
\hline Tidak Anemia & 22 & 46,8 & 35 & 74,5 & \\
\hline
\end{tabular}


Tabel 2. Uji Hubungan Faktor Risiko Responden dengan Kejadian Kematian Bayi

\begin{tabular}{|c|c|c|c|c|c|}
\hline \multirow[t]{2}{*}{ Variabel } & \multicolumn{2}{|c|}{ Kasus } & \multicolumn{2}{|c|}{ Kontrol } & \multirow[t]{2}{*}{ P-value (OR) } \\
\hline & $\mathrm{f}$ & $\%$ & $\mathrm{f}$ & $\%$ & \\
\hline \multicolumn{6}{|l|}{ Pengetahuan } \\
\hline Tinggi $>18$ & 26 & 55,3 & 31 & 66,0 & \multirow[t]{2}{*}{$0,291(0,639)$} \\
\hline Rendah $<18$ & 21 & 44,7 & 16 & 34,0 & \\
\hline \multicolumn{6}{|l|}{ Paritas } \\
\hline Berisiko & 21 & 46,8 & 14 & 63,8 & \multirow{2}{*}{$0,135(1,904)$} \\
\hline Tidak Berisiko & 26 & 53,2 & 33 & 36,2 & \\
\hline \multicolumn{6}{|l|}{ Jarak kehamilan } \\
\hline Berisiko $(<2$ tahun $)$ & 4 & 14,8 & 4 & 12,1 & \multirow[t]{2}{*}{$1,000(1,000)$} \\
\hline Tidak Berisiko (>2tahun) & 23 & 85,2 & 29 & 87,9 & \\
\hline \multicolumn{6}{|l|}{ Berat badan ibu } \\
\hline Kurang & 17 & 36,2 & 14 & 29,8 & \multirow[t]{2}{*}{$0,510(1,336)$} \\
\hline Normal & 30 & 63,8 & 33 & 70,2 & \\
\hline \multicolumn{6}{|l|}{ LILA } \\
\hline Kurang & 12 & 25,5 & 12 & 25,5 & \multirow[t]{2}{*}{$1,000(1,000)$} \\
\hline Normal & 35 & 74,5 & 35 & 74,5 & \\
\hline \multicolumn{6}{|l|}{ Riwayat penyakit kronik } \\
\hline Ada & 11 & 23,4 & 7 & 14,9 & \multirow[t]{2}{*}{$0,294(1,746)$} \\
\hline Tidak & 36 & 76,6 & 40 & 85,1 & \\
\hline \multicolumn{6}{|l|}{$\begin{array}{l}\text { Kejadian Perdarahan saat } \\
\text { hamil }\end{array}$} \\
\hline Iya & 7 & 14,9 & 3 & 6,4 & \multirow[t]{2}{*}{$0,181(2,576)$} \\
\hline Tidak & 40 & 85,1 & 44 & 93,6 & \\
\hline \multicolumn{6}{|l|}{ Hipertensi } \\
\hline Iya & 4 & 8,5 & 3 & 6,4 & \multirow[t]{2}{*}{$0,694(1,364)$} \\
\hline Tidak & 43 & 91,5 & 44 & 93,6 & \\
\hline \multicolumn{6}{|l|}{ Penolong persalinan } \\
\hline Petugas Kesehatan & 45 & 95,7 & 44 & 93,6 & \multirow[t]{2}{*}{$0,646(1,534)$} \\
\hline Bukan Petugas Kesehatan & 2 & 4,3 & 3 & 6,4 & \\
\hline \multicolumn{6}{|l|}{ Literasi } \\
\hline Baik(>38,76) & 25 & 53,2 & 23 & 48,9 & \multirow[t]{2}{*}{$0,680(1,186)$} \\
\hline Rendah $(<38,76)$ & 22 & 46,8 & 24 & 51,1 & \\
\hline Berat Badan & & & & & \\
\hline Kurang & 17 & 36,2 & 14 & 29,8 & $0,510(1,336)$ \\
\hline Normal & 30 & 63,8 & 33 & 70,2 & \\
\hline Asfiksia & & & & & \\
\hline Iya & 28 & 59,6 & 3 & 6,4 & $0,001(21,614)$ \\
\hline Tidak & 19 & 40,6 & 44 & 93,6 & \\
\hline Kelainan konginetal & & & & & \\
\hline Iya & 15 & 31,9 & 0 & 0 & $0,001(2,469)$ \\
\hline Tidak & 32 & 68,1 & 47 & 100 & \\
\hline Kelahiran Prematur & & & & & \\
\hline Iya & 11 & 23,4 & 3 & 6,4 & $0,020(4,481)$ \\
\hline Tidak & 36 & 76,6 & 44 & 93,6 & \\
\hline
\end{tabular}


Hasil uji statistik menunjukkan bahwa umur tidak memiliki hubungan signifikan dengan kejadian kematian bayi. Meskipun tidak terdapat hubungan antara umur ibu dengan kejadian kematian bayi namun yang perlu diwaspadai bila umur ibu hamil $<20$ tahun yang merupakan usia rentan karena masih pada tahap masa reproduksi awal dan organ reproduksi belum tumbuh secara sempurna sehingga dapat beresiko terjadi gangguan pertumbuhan janin saat dikandungan, sedangkan pada usia lebih dari 35 tahun seorang ibu sudah mulai muncul berbagai macam penyakit yang menurunkan kemampuan ibu untuk melakukan proses persalinan normal karena usia maupun penyakit kronik yang dialaminya. ${ }^{(9)}$ Demikian juga faktor pendidikan, dan paritas,

Penelitian ini juga menunjukkan bahwa LILA ibu dari uji Chi-Square dapat diketahui bahwa nilai p-value 1,000 $(>0,05)$, yang artinya tidak ada hubungan yang bermakna antara besar lingkar lengan atas (LILA) ibu dengan kematian bayinya. Besar LILA ibu $<23,5 \mathrm{~cm}$ merupakan indikator status gizi pada saat ibu hamil beresiko tergolong kekurangan energi kronik (KEK. Pada penelitian memang tidak ada hubungan antara LILA dengan kejadian kematian bayi namun perlu diwaspadai bila ibu hamil dengan status gizi KEK sebelum usia kehamilan mencapai 16 minggu harus di tindak lanjuti dengan mengatasi status gizinya karena berisiko melahirkan bayi BBLR. Bayi yang dilahirkan dengan BBLR akan mengalami hambatan petumbuhan dan perkembangan serta kemunduran pada fungsi otak dan kehilangan masa golden period yang juga berisiko tinggi mengalami kematian. ${ }^{(10)}$ Selain itu ibu dengan KEK yang berkepanjangan akan mengalami anemia. Terdapat keterkaitan hubungan antara ibu hamil dengan KEK, Anemia dan kejadian BBLR. Ibu hamil dengan KEK mempunyai risiko 2 kali untuk melahirkan bayi BBLR di bandingkan dengan yang tidak mengalami KEK. ${ }^{(10)}$ Demikian juga ibu yang anemia saat hamil kemungkinan mempunyai resiko untuk melahirkan bayi yang BBLR. ${ }^{(10)}$

Dari uji Chi-Square dapat diketahui bahwa nilai p-value $0,006(<0,05)$ yang artinya ada hubungan yang bermakna antara riwayat anemia saat ibu hamil dengan kematian bayinya. Hasil nilai $\mathrm{OR}=3,314$ berarti ibu dengan riwayat anemia mempunyai risiko 3,314 kali lebih besar untuk terjadinya kematian bayi dibandingkan dengan ibu yang tidak mempunyai riwayat anemia. Riwayat anemia ibu saat hamil menjadi hal yang perlu segera diatasi agar status ibu pada saat pemeriksaan berikutnya ibu tidak lagi mengalami anemia karena telah diberikan tablet ferrum pada saat trimester kedua dan 
ketiga, sehingga memungkinkan anemia pada awal kehamilan dapat diatasi dengan ditambah asupan nutrisi yang baik kepada ibu dan pada akhirnya status kesehatan ibu yang baik dapat mencegah bayi yang dilahirkan dalam kondisi BBLR. Selain itu ibu hamil dengan KEK yang kemudian mengalami anemia tetapi telah diberikan makanan tambahan oleh bidan untuk meningkatkan status gizinya dapat memberikan dampak yang baik terhadap nutrisi bayi yang dikandungnya. Ibu hamil dengan anemia berpengaruh terhadap janin seperti: Keguguran, kematian dalam kandungan, persalinan kurang bulan/prematur, meningkatkan kejadian BBLR, kelainan kongental, kematian perinatal karena infeksi, dan intelegensia anak menjadi rendah. ${ }^{(10)}$

Selain itu penelitian ini juga memperlihatkan dari uji Chi-Square nilai p-value $0,000(<0,05)$ yang artinya ada hubungan yang bermakna antara bayi yang mengalami asfiksia dengan kejadian kematian bayi dengan nilai OR sebesar 21,614 yang menunjukkan bahwa bayi yang mengalami asfiksia saat dilahirkan mempunyai risiko 21,614 kali lebih besar untuk terjadinya kematian dibandingkan dengan bayi yang tidak mengalami asfiksia. Sejalan dengan penelitian Mahmudah bahwa bayi dengan asfiksia mempunyai risiko kematian 2,270 kali lebih besar dibandingkan dengan bayi yang tidak asfiksia . ${ }^{(1)}$ Pada penelitian ini terdapat 59,6\% kasus kematian bayi yang bayinya mengalami asfiksia setelah dilahirkan dan 6,4\% kasus asfiksia pada bayi yang tidak mengalami kematian (kontrol).

Dalam hal kelainan kongenital, terdapat $31,9 \%$ terjadi pada kelompok kasus kematian bayi, sedangkan pada kelompok control tidak terdapat kasus kelainan kongenital. Terdapat hubungan antara faktor kelainan kengenital dengan kejadian kematian bayi dengan $\mathrm{p}$ value 0,001 dan nilai OR 2,469 yang artinya bayi yang mengalami kelainan kongenital mempunyai risiko 2,469 kali lebih besar untuk mengalami kematian dibandingkan dengan bayi yang tidak mengalami kelainan kongenital saat dilahirkan. Hasil penelitian peneliti sebelumnya juga menghasilkan hal yang serupa yaitu bayi yang mengalami kelainan kongenital mempunyai risiko 2,205 kali lebih tinggi untuk terjadi kematian perinatal dibandingkan dengan bayi yang tidak mengalami kematian bayi terutama pada periode perinatal. ${ }^{(11)}$ Pada penelitian ini memperlihatkan bahwwa sebanyak 31,9\% bayi yang dilahirkan mengalami kelainan kongenital pada kelompok kasus dengan jenis kelainan bawaan berupa anensefalus, atresia ani, kelainan jantung, kelainan katup jantung, dan kelainan pembuluh darah, serta bayi yang mengalami fruktur 
distorsia bahu sehingga memungkinkan bayi yang dilahirkan tidak bisa bertahan hidup. Kebanyakan dari jenis kelainan kongenintal ini menyebabkan bayi meninggal dan sukar ditangani. Faktor penyebab langsung kelainan kongenital seringkali sukar diketahui, sekitar $40 \%$ tidak diketahui dengan pasti penyebabnya. Pertumbuhan janin atau fetus dapat disebabkan oleh beberapa faktor seperti: faktor genetika, kromosom, infeksi, faktor ibu, faktor mekanik dan lingkungan, atau gabungan dari berbagai faktor tersebut secara bersama-sama mempengaruhi kesehatan bayi . ${ }^{(1)}$

Faktor kelahiran prematur juga menjadi faktor resiko terhadap kematian bayi. Dari uji Chi-Square dapat diketahui bahwa nilai $p=0,020(<0,05)$, yang artinya ada hubungan yang bermakna antara umur kehamilan/kelahiran bayi prematur terhadap kejadian kematian bayi. Hasil nilai OR menunjukkan 4,481, yang berarti bahwa bayi yang dilahirkan prematur mempunyai risiko 4,481 kali lebih besar untuk terjadinya kematian dibandingkan dengan bayi yang dilahirkan dari kehamilan cukup umur. Sejalan dengan penelitian lain yang menunjukan lebih dari $50 \%$ kematian bayi yang telah diidentifikasi berasal dari bayi yang dilahirkan prematur. ${ }^{(12)}$ Terdapat beberapa kasus bayi yang lahir prematur, dibarengi dengan BBLR dan juga asfiksia serta adanya riwayat kelahiran prematur pada kehamilan sebelumnya. Sehingga semakin banyak faktor risiko yang dipunyai maka semakin mempertinggi risiko bayi mengalami kematian. Melahirkan prematur juga banyak terjadi bila umur ibu $<18$ tahun atau >40 tahun, ibu mempunyai tekanan darah tinggi, pertumbuhan janin yang lambat, retensi plasenta, ketuban pecah dini/KPD, Infeksi rahim, kehamilan kembar. Selain itu penyakit periodontal, riwayat persalinan prematur sebelumnya, serta ibu hamil dengan KEK, paparan rokok yang tinggi dan sering minum minuman beralkohol dapat mempercepat kelahiran prematur. ${ }^{(13)}$

Faktor risiko lain yang dapat mempengaruhi kejadian kematian bayi adalah faktor komplikasi persalinan, dalam penelitian ini memperlihatkan kelompok kasus lebih banyak yang mengalami komplikasi dalam persalinan $(23,4 \%)$ dibanding dengan kelompok kontrol (14,9\%). Dari uji Chi-Square dapat diketahui bahwa nilai $p=0,001(<0,05)$, yang artinya ada hubungan yang bermakna antara kejadian komplikasi saat persalinan terhadap kejadian kematian bayi. Hasil nilai OR menunjukkan 11,613, yang berarti bahwa bayi yang saat dilahirkan terjadi komplikasi persalinan mempunyai risiko 11,613 kali lebih besar untuk terjadinya kematian dibandingkan dengan bayi yang saat dilahirkan tidak terjadi komplikasi. 
Komplikasi persalinan sering terjadi adalah akibat dari keterlambatan penanganan persalinan, dan dianggap sebagai salah satu penyebab terjadinya kematian ibu bersalin. Faktor-faktor yang diduga ikut berhubungan dengan kejadian komplikasi tersebut antara lain usia, pendidikan, status gizi dan status ekonomi ibu bersalin. ${ }^{(13)}$

Faktor lain yang merupakan faktor risiko, tetapi dalam penelitian ini tidak menyebabkan kematian bayi adalah pengetahuan ibu (p-value 0,291), Pendidikan ibu ( $\mathrm{p}$-value 0,557), Paritas (pvalue 0,135), Jarak kehamilan (p-value 1,000), berat badan ibu (p-value 0,510), LILA ibu (p-value 1,000), riwayat penyakit kronik ibu (p-value 0,294), perdarahan (pvalue 0,181), hipertensi ( $\mathrm{p}$-value 0,694), penolong persalinan ( $\mathrm{p}$-value 0,646), literasi ibu (p-value 0,680). Seluruh variable tersebut secara statistik tidak berhubungan dengan kejadian kematian bayi.

\section{SIMPULAN}

Dari karakteristik ibu dan faktor risiko terjadinya kematian bayi, diperoleh bahwa faktor asfiksia dengan p-value 0,$000 ; \mathrm{OR}=21,614$, kelainan kongenital dengan $\mathrm{p}$-value 0,$000 ; \mathrm{OR}=2,469$ dan bayi prematur dengan $\mathrm{p}$-value 0,020 ; $\mathrm{OR}=$ 4,481 memiliki hubungan terhadap kematian bayi. Demikian juga komplikasi persalinan dengan p-value 0,$000 ; \mathrm{OR}=$
11,613 dan, riwayat anemia ibu saat hamil dengan $\mathrm{p}$-value 0,$006 ; \mathrm{OR}=3,314$, mempunyai hubungan dengan kejadian kematian bayi.

Dari hasil studi ini disarankan bahwa petugas kesehatan diharapkan dapat mencegah terjadinya asfiksia pada bayi dan kelainan kongenital serta kelahiran prematur dan anemia pada ibu saat hamil dengan cara melakukan ANC tepat waktu dan lengkap pada ibu hamil termasuk pemberian tablet Fe kepada ibu dan memonitornya melalui petugas surveilance KIA. Petugas kesehatan diharapkan untuk rutin mengunjungi ibu hamil di daerah yang aksesnya sulit dan jauh dari pelayanan kesehatan meskipun sudah terdapat bidan desa dan polindes. Bila terdapat ibu hamil yang tidak memeriksakan kehamilan karena kesulitan akses ke pelayanan kesehatan lebih dapat terpantau. Petugas kesehatan perlu melakukan pemetaan ibu hamil risiko tinggi sebagai upaya sistem kewaspadaan dini. Selain itu ibu hamil diharapkan aktif memeriksakan kehamilan pada pelayanan kesehatan yang tersedia, dan perlunya dukungan dari keluarga dan masyarakat.

\section{KEPUSTAKAAN}

1. Rakorpop Kementrian Kesehatan Republik Indonesia. Kesehatan Dalam Kerangka Sustainable Development Goals (SDGs). 2015;(97). 
2. Dinas Kesehatan Provinsi Jawa Tengah. Profil Kesehatan Provinsi Jawa Tengah Tahun 2012. Pemerintah Provinsi Jawa Teng. 2012;3511351(24).

3. Dinas Kebupaten Banjarnegara. Profil Kesehatan Banjarenegara Tahun 2012. Dinas Kesehat Kabupaten Banjarnegara. 2013;

4. Banjarnegara DKK. Profil Kesehatan Banjarnegara Tahun 2014. Dinas Kesehat Kabupaten Banjarnegara. 2014;

5. Radar Banyumas. Penurunan AKB dan AKI Belum Signifikan. Radar Banyumas.co.id [Internet]. 2017;2017. Available from: http://radarbanyumas.co.id/didugakurang-giz-bayi-kembar-meninggalusai-dilahirkan/

6. Seputar Banjarnegara. Bupati banjarnegara Menyerahkan empat unit mobil ambulance dalam memperingati hari kesehatan Nasional. Seputar banjar.com [Internet]. 2017;2017. Available from: http://www.seputarbanjar.com/2017/11 /12/bupati-serahkan-4-unit-ambulance/

7. Radar Banyumas. Diduga Kurang Gizi, Bayi Kembar Meninggal Usai Dilahirkan. Radar Banyumas.co.id [Internet]. 2017;2017. Available from: http://radarbanyumas.co.id/didugakurang-giz-bayi-kembar-meninggalusai-dilahirkan/

8. Radar Banyumas. Bidan Desa Banjarnegara Harus Lebih Sigap Untuk Menekan Angka Kematian Ibu dan Bayi. Radar Banyumas [Internet]. 2017;2017. Available from: http://radarbanyumas.co.id/bidan-desabanjarnegara-harus-lebih-sigap-untukmenekan-angka-kematian-ibu-danbayi/

9. Manuaba IBG. Ilmu Kebidanan, Penyakit Kandungan, dan Keluarga Berencana untuk Pendidikan Anak. Jakarta: EGC; 1998. 36 p.

10. Kementrian Kesehatan Republik Indonesia. Pegangan Fasilitator Kelas Ibu Hamil. Jakarta: Kementrian Kesehatan RI: Katalog Dalam Terbitan (KDT); 2014.

11. Mahmudah U. Di Kabupaten Batang Tahun 2010. Semarang: Universitas Negeri Semarang; 2011.

12. Kusuma A, Indawati R. Faktor Penyebab Kematian Bayi Di Kabupaten Sidoarjo. Dep Biostat dan Kependud FKM UNAIR. 2015;1(2010):33-42.

13. Sukarni I, Sudarti. Patologi Kehamilan, Persalinan, Nifas dan Neonatus Resiko Tinggi. 2014. 